\title{
O PAPEL DA SUPERINTENDÊNCIA ESCOLAR NA GESTÃO EDUCACIONAL DE FORTALEZA/CE
}

http://dx.doi.org/ 10.5902/2318133861908

\author{
Esmeraldina Sousa de Sousa ${ }^{1}$ \\ Eloisa Maia Vidal ${ }^{2}$
}

\begin{abstract}
Resumo
Por meio deste texto apresenta-se resultados de pesquisa que tratou da atuação da Superintendência Escolar na rede municipal de Fortaleza/CE. A pesquisa foi de natureza qualitativa, com análise documental, entrevistas e questionários aplicados à oito sujeitos. Constatou-se que o superintendente escolar atua monitorando indicadores, processos e instrumentos de gestão, é um cargo que tem um padrão de exigência e de atribuições complexo, uma vez que funciona como uma interface entre a gestão superior e as escolas, exigindo competências técnicas e habilidades profissionais de ordem superior e que os gestores escolares consideram o superintendente um parceiro na busca pelos resultados embora sintam-se responsabilizados pelos resultados de suas escolas.

Palavras-chave: gestão educacional, gestão escolar, superintendência escolar.
\end{abstract}

\section{THE ROLE OF SCHOOL SUPERINTENDENCE IN THE EDUCATIONAL MANAGEMENT OF FORTALEZA/CE}

\begin{abstract}
This paper analyses the school superintendency of the city schools of Fortaleza/CE. The research is qualitative, through documental analysis and interviews with questionnaires applied to eight subjects. We concluded that the school superintendent monitors key indicators, processes and management tools, is a position with high standards and complex assignments, once it works as an interface between top management and schools, demanding technical competencies and professional skills of high order and the school managers consider the superintendent a partner in the search for results, although they feel pressed and charged and liable for the results of their schools.

Key-words: educational management, school management, school superintendency.
\end{abstract}

1 Prefeitura Municipal de Fortaleza, Brasil. E-mail: esmeraldinajs@gmail.com.
2 Universidade Estadual do Ceará, Brasil. E-mail: eloisamvidal@yahoo.com.br.

Regae: Rev. Gest. Aval. Educ. Santa Maria v. 10 n. 19 e61908, p. 1-20 2021 


\section{Introdução}

L ste artigo apresenta resultados de pesquisa que teve como objetivo apresentar um diagnóstico e caracterização da gestão escolar na rede pública municipal de Fortaleza/CE. De natureza qualitativa foi realizada junto à oito sujeitos, quatro diretores e quatro superintendentes escolares, no ano de 2019. Procurouse analisar as principais motivações que levaram a Secretaria Municipal de Educação SME - a criar o cargo de superintendente escolar, suas principais atribuições, processo de escolha para o cargo, as tarefas relacionadas as atividades cotidianas, bem como os processos de avaliação e formação, as mudanças observadas no marco legal e nos procedimentos administrativos.

A rede municipal de educação de Fortaleza/CE é a quarta maior em quantidade de matriculas entre as capitais brasileiras e possui 299 estabelecimentos de ensino (Inep, 2019) que atendem educação infantil, ensino fundamental e educação de jovens e adultos. Ao longo dos últimos vinte anos cresceu de forma expressiva em decorrência de medidas adotadas pelo governo do Estado do Ceará em relação a municipalização dos anos iniciais e finais do ensino fundamental, o que ocorreu em momento imediatamente posterior à publicação da LDB de 1996. Em Fortaleza/CE a municipalização dos anos iniciais do ensino fundamental ocorreu no início dos anos 2000, enquanto a municipalização dos anos finais ainda se encontra em andamento.

$O$ processo de municipalização do ensino fundamental aconteceu num momento marcada pela ampliação desta etapa para nove anos de duração - lei n. 11.274/2006 -, o aumento da obrigatoriedade da educação básica para 4 a 17 anos - emenda constitucional n. 59/2009 -, o que estimulou o crescimento das matrículas na escola infantil, o aumento no número de docentes e a ampliação dos serviços relativos aos programas suplementares. As alterações na base legal geraram o crescimento da rede escolar da capital e sua complexidade, passando a demandar a implantação de novos mecanismos de gestão, considerando especialmente estratégias de monitoramento e acompanhamento.

Desde 1997 a SME mantém seis instâncias intermediárias denominadas Distritos de Educação - DE. Esses distritos foram criados para atender, de forma descentralizada, a um determinado quantitativo de escolas no território sobre o qual cada um deles tem jurisdição (Fortaleza, 2001). As atribuições dos distritos envolvem a implantação de iniciativas nos âmbitos administrativo, pedagógico e financeiro, em que se destaca a descentralização das decisões; o acompanhamento as atividades pedagógicas de forma efetiva e a parceria quanto ao trabalho escolar.

A partir de 2013 teve início uma nova gestão na Prefeitura de Fortaleza, que do ponto de vista político-ideológico é alinhada com o mesmo grupo que está à frente do governo do Estado. Essa característica tornou mais fluída a migração do modelo de gestão por resultados (Holanda, 2006) adotado pela Secretaria de Educação do Estado, para a educação municipal, incluindo equipes técnicas que são cedidas para a rede municipal. Esse momento também foi marcado pelo fortalecimento das avaliações de larga escala que se iniciou com a criação do Índice de Desenvolvimento da Educação Básica em 2007, com a realização do Saeb de forma censitária nas escolas públicas e a criação de metas bianuais para as escolas com projeções até 2021. No Ceará, também a partir deste ano, foi criada uma política de accountability com mecanismos de 
responsabilização junto aos municípios, tendo como base a nova lei ICMS, em que 18\% dos $25 \%$ da cota-parte dos municípios estão vinculados a resultados educacionais e a criação do Prêmio Escola Nota 10 (Costa, 2020).

Essa confluência de mudanças no âmbito da política educacional nacional e estadual induziu a gestão municipal a redesenhar não só a implantação de suas iniciativas junto às escolas, mas a reorganizar e criar mecanismos de acompanhamento e monitoramento junto as escolas e as equipes escolares. Foi nesse contexto que, a partir de 2013, a gestão educacional de Fortaleza/CE implantou um conjunto de mudanças do ponto de vista administrativo e pedagógico nos Distritos de Educação. Este artigo analisa a base legal que orientou a referida mudança, observando as principais características e impactos sobre as escolas no que tange a monitoramento e acompanhamento, considerando os depoimentos de oito sujeitos envolvidos no processo.

\section{Metodologia}

Trata-se de uma pesquisa qualitativa realizada por meio de análise documental leis, decretos, resoluções, editais e outras regulamentações sobre a gestão educacional de Fortaleza/CE e entrevistas semiestruturadas qualitativas realizadas no intervalo entre agosto e novembro 2019 com oito sujeitos.

Posteriormente houve o processamento da informação e a subsequente análise em três etapas: consolidação e seleção de material; escolha do universo de sujeitos investigados e análise dos questionários e das entrevistas.

As entrevistas aplicadas com os superintendentes tiveram como propósito examinar e analisar suas experiências subjetivas e conhecer suas trajetórias de vida e profissional, as motivações internas e externas para exercer a referida função, os obstáculos experimentados no acesso e no desempenho do cargo, os mecanismos para superá-los, as consequências e contrapartes pessoais e profissionais do desempenho da administração, as características e estilos da administração, a percepção de como eles realizam seu trabalho.

\section{O contexto da reforma administrativa da SME de Fortaleza/CE}

As pressões para cortar orçamento e aumentar a eficiência, mantendo o desempenho, levaram os gestores públicos a recorrer ao setor privado em busca de soluções. Assim, como um meio de reorganização de processos e estruturas administrativas governamentais e reduzir a burocracia, a ideia de reengenharia dos processos foi introduzida no âmbito das organizações públicas (Falsarella, 2018; Frigotto; Ciavatta, 2003).

Além disso, no que concerne à seara da educação, destaca-se o importante papel desempenhado pelos organismos multilaterais na formulação de políticas educacionais nesse mesmo período. É por influência de agências como a Unesco, Banco Mundial e OCDE que as avaliações de larga escala adentram a política educacional brasileira e se capilarizam por todos os sistemas de ensino.

Por conta da aplicação de preceitos da reengenharia de processos governamentais RPG - e da nova gestão pública - NGP - ao contexto da educação, especialmente no que concerne aos gestores escolares, têm surgido políticas voltadas para a profissionalização e empoderamento dos diretores (Pina, 2015; Parente, 2017), ao mesmo tempo que tem 
sido atribuído o monitoramento de indicadores educacionais e as avaliações externas do desempenho escolar. Considerando o quantitativo de escolas municipais o desafio de monitorar e acompanhar o andamento da gestão escolar em busca de melhoria de indicadores requeria a reorganização das instâncias intermediárias da gestão educacional assim como a centralização de bases de dados para que a relação órgão central, órgãos intermediários e escolas se estruturasse a contento no modelo de gestão por resultados.

Assim, o projeto de mudanças na administração da educação pública de Fortaleza/CE se estabeleceu, a priori, como expressão da vontade política de transformar a educação e seus resultados. É com esse propósito que emergiram novos agentes fundamentais na implantação das políticas educacionais, que contribuiriam para a geração de capacidade transformadora e que atuariam com mecanismos de monitoramento dos processos e resultados. Nesse contexto local particular o que esta iniciativa demonstra é o objetivo de alterar os modos de regulação dos poderes públicos no sistema escolar (Barroso, 2005).

A disponibilidade de informações pertinentes às demandas educacionais tornou-se um fator prioritário nas agendas de trabalho dos sistemas e redes de ensino, o que tem levado a uma proliferação crescente e contínua de iniciativas voltadas à produção de estatísticas educacionais. Mais especificamente os indicadores educacionais estão se tornando cada vez mais relevantes para a tomada de decisões.

Diante da necessidade de uma nova arquitetura de cargos da educação pública municipal foi criada a função de Superintendência Escolar ao nível do órgão central e dos órgãos regionais - Distritos de Educação -, a quem foi definida um conjunto de atribuições relacionadas ao monitoramento e controle dos indicadores educacionais das escolas. A ideia foi inspirada em experiências já existentes como as das secretarias estaduais de educação do Ceará, Minas Gerais, Rio de Janeiro e Rio Grande do Sul e secretarias municipais de Sobral/CE e Juazeiro do Norte/CE, em que os responsáveis funcionam como um elo entre o órgão central e as escolas e desempenham um papel importante no processo de acompanhamento sistemático de indicadores educacionais em intervalos regulares de tempo, por meio de instrumentos estatísticos, de avaliação e controle da qualidade educacional.

O cargo foi criado por meio da lei n. 169/2014. No organograma da SME a Superintendência Escolar é subordinada à Coordenadoria de Articulação da Comunidade e Gestão Escolar - Cogeste -, que representa um dos dezesseis órgãos de execução programática previstos no decreto n. 14.450/2019. Nos seis distritos de educação a superintendência escolar está alocada na Célula de Acompanhamento e Superintendência Escolar.

De acordo com o art. 57 da lei n. 169/2014 são treze as atribuições do cargo de Superintendente Escolar, entre as quais estão previstas orientar e organizar os processos, responsabilidades e atividades da gestão escolar em todas as instâncias escolas, distritos e secretaria -, bem como criar procedimentos para a conexão e fomento de informações entre essas instâncias. Ou seja, oferece atendimento integrando os níveis de atenção aos gestores escolares nos distritos de educação - instâncias mais próximas às escolas - e na Secretaria -descentralização geográfica. 
A criação da Superintendência Escolar pode ser entendida como um elemento novo na forma que até então o sistema público municipal se organizava e tem servido a pelo menos dois propósitos importantes e articulados. O primeiro tem por objetivo criar uma estrutura-de descentralização horizontal em que o poder de decisão pode permanecer com os agentes de gestão dos órgãos regionais no sistema de autoridade formal. $O$ segundo se refere à racionalização administrativa imposta pela racionalidade técnica, introduzindo no processo educacional os pressupostos de supervisão permanente, otimização da competência especializada e escassa; homogeneidade do acompanhamento para fins de resultados e identificação de focos de ineficiência.

A legislação não explicitou a função dos superintendentes escolares como gestores no âmbito dos sistemas de ensino mas, na prática, se constatou a intensificação do trabalho polarizado na figura do superintendente, ao qual foram atribuídas muitas das funções que no passado era distribuídas por diversos servidores da SME e dos distritos de educação. O superintendente passou a ser o catalizador de informações sobre um conjunto de escolas, via de regra, utilizando sistemas informatizados que permitem compilar os dados nos mais diversos formatos, o que o torna conhecedor de informações sobre a gestão de uma determinada escola, em algumas situações, com maior nível de detalhamento do que o próprio gestor escolar.

Ou seja, os superintendentes escolares representam uma categoria de profissionais de educação com os atributos gerenciais para acompanhar e controlar a gestão escolar na rede pública municipal de Fortaleza/CE por meio de provisão de ferramentas de gestão sem preocupação com a formação dos gestores em áreas como: processos de desenvolvimento da escola, padrões mínimos de funcionamento, planos de gestão e plano de carreira do magistério.

No art. 57 da lei n. 169/2014 estão atribuições previstas para os superintendentes escolares:

I. Acompanhar e monitorar os indicadores: frequência de alunos, professores e funcionários; movimento, rendimento e fluxo escolar; desempenho acadêmico em avaliações externas e internas; ambiente educativo e espaço físico das escolas de sua abrangência;

II. Acompanhar e monitorar os processos escolares: matrícula e lotação; planejamento pedagógico; prática pedagógica e avaliação da aprendizagem das escolas de sua abrangência;

III. Acompanhar e monitorar os instrumentos de gestão: Calendário Escolar; Regimento Interno; Plano de Ação; Projeto Político Pedagógico e Plano de Desenvolvimento da Escola das unidades de ensino de sua abrangência;

IV. Realizar visitas periódicas às escolas que acompanha;

V. Elaborar relatórios das visitas realizadas às escolas;

VI. Planejar e promover encontros sistemáticos com os diretores escolares das unidades de ensino que acompanha para realizar estudos sobre os indicadores de desempenho e rendimento dos alunos;

VII. Organizar a pauta de reuniões dos diretores escolares com o Distrito de Educação;

VIII. Realizar audiência individual com os diretores escolares das escolas que acompanha, caso necessário; 
IX. Monitorar a alimentação do Sistema de Gestão Acadêmica (SGA) pelas escolas de sua responsabilidade;

$X$. Consolidar dados e indicadores das escolas de sua abrangência;

XI. Realizar contato com os diretores escolares para solicitar e/ou passar informações/orientações do Distrito Educacional/SME;

XII. Despachar processos referentes às unidades de ensino que acompanha;

XIII. Realizar estudos sobre os programas e políticas implementadas pela Secretaria Municipal de Educação de Fortaleza.

A partir dessas atribuições é possível perceber se constrói uma cadeia de elos conectados entre si para acompanhar o processo de monitoramento e o fluxo de comunicação entre as instituições envolvidas, como mostra a figura 1.

Figura 1 -

Fluxo de comunicação da rede pública municipal de Fortaleza/CE.



Fonte: autoras (2020).

Outro ponto observado é que a Superintendência atua considerando uma concepção de gestão escolar que prevê diretores focados no trabalho pedagógico, mobilizando-os por meio de um trabalho em que cada um é corresponsável pela qualidade do ensino ofertado, pela aprendizagem dos alunos e pelos resultados globais da escola e da rede pública municipal como um todo.

A perspectiva apontada pelo art. 57 da lei n. 169/2014 é que o trabalho da Superintendência abrange um leque de atribuições no campo da gestão escolar, mas sempre com vistas ao monitoramento e acompanhamento. Nesse sentido não tem se registrado conflito de atribuições no exercício da gestão escolar. Dentre as principais ações, processos escolares e instrumentos de gestão acompanhados pelos superintendentes escolares entrevistados, destacam-se:

a) Reuniões de polo: reunião de agrupamento de diretores escolares por distritos escolares e zonas de proximidade - denominadas de polos - ou por segmentos de oferta. Exemplo: escolas que oferecem educação infantil; ou escolas que ofertam o ensino fundamental anos finais - $6^{\circ}$ ao $9^{\circ}$ ano.

b) Caminhadas pedagógicas: atividade realizada durante as visitas às escolas em que o superintendente e o diretor escolar realizam uma vistoria na infraestrutura física da escola. Esta observação do espaço físico serve de indicador de eficiência e organização da escola, momento em que o superintendente escolar percebe as condições de limpeza, organização e senso estético, associados ao cuidado e respeito com a comunidade escolar. 
c) Visitas sistemáticas às escolas: trata-se de fiscalização periódica realizada quinzenalmente ou mensalmente. É uma obrigação do superintendente ir até as escolas que acompanha e reunir-se com o diretor levando uma pauta que, a posteriori, servirá de subsídio para o relatório, com informações sobre o funcionamento de cada escola;

d) Alimentação de sistemas e retroalimentação: trata-se da inserção de dados coletados nas visitas às escolas em sistemas informatizados da SME e o feedback, ou seja, o retorno das informações ou dos processos às escolas.

Comparando o que prevê a legislação e as informações obtidas durantes as entrevistas é possível afirmar que a Superintendência representa a correição, a auditoria, a orientação e a assistência técnico-administrativa e pedagógica. Esses profissionais funcionam como os olhos e os ouvidos do Poder Executivo nas escolas e são vistos como elos importantes entre a SME e os distritos de educação na busca pela uniformização dos procedimentos e na implementação de políticas educacionais. Além disso auxiliam os gestores escolares nas decisões e encaminhamentos a fim de solucionar os problemas do cotidiano da escola, com o objetivo de buscar a melhoria da qualidade no processo ensino e aprendizagem. Na visão das superintendentes, o trabalho envolve o acompanhamento das múltiplas dimensões da gestão escolar, o que exige delas competências e habilidades diversas, como mostra os depoimentos a seguir:

"Para a gente acompanhar uma escola como superintendente, tem que saber tudo que o diretor faz. Tudo, tudo! Todas as dimensões de acompanhamento: a pedagógica, a financeira, a administrativa, a relacional. São aspectos do acompanhamento que a gente tem que observar em cada visita; em cada relatório que faz; em cada mediação que faz; porque também tem muitas questões de conflitos que a gente tem que ajudar o diretor. Todas as nossas orientações são voltadas para uma dessas dimensões". (S3)

"Na Superintendência a gente tem uma ampla visão da gestão. A gente passa daquele conhecimento micro, que tem a princípio, quando chega na escola, para o macro, como um todo. Você vê a parte administrativa, o financeiro, o pedagógico, você vê todo o burocrático, os relacionamentos, você vê tudo do gestor. Você conhece não só uma escola, mas você começa a conhecer várias escolas. (...) E aí você vê o trabalho do diretor em diferentes perspectivas." (S6)

"Nós trabalhamos na orientação dos gestores, no fortalecimento do trabalho deles, que eles desempenham no âmbito da escola. [...] $\mathrm{Na}$ superintendência, nós acompanhamos muito de perto essas atividades, que os gestores executam diariamente. Então nosso trabalho é muito de orientação também dessas atividades de gestão. Nós sempre estamos nesse diálogo com o gestor, de forma que ele organize a rotina dele de trabalho diário, que ele tenha aquelas atividades a desempenhar." (S5)

O que se depreende dos relatos é que o trabalho do superintendente não se restringe a um mero acompanhamento e registro das atividades atinentes à gestão escolar e seus resultados, mas chega a influenciar a rotina diária do gestor no que ele deve e como fazer. Assim, pode ser considerado um poder paralelo que abrange múltiplas funções como: 
a) Verificadora: deve possuir domínio da legislação - observância de normas regulamentos - e ser observador.

b) Avaliadora: compreender os dados, índices e estatísticas relacionadas ao uso dos recursos, para inferir sobre a realidade, perceber as evidências significativas para a interpretação das situações contextuais.

c) Orientadora: possuir escuta ativa; ter boa comunicação oral e escrita; promover reflexões; ser conciliador.

d) Corretiva: ter segurança e postura pedagógica e ser estratégico - ter consciência do que deseja alcançar - o que implica em metas, prazos a cumprir e muito planejamento, focar nos objetivos da organização e saber lidar com os desafios.

e) Realimentadora: possuir criatividade, celeridade e movimentação dos processos e feedbacks.

Os diretores apontam certa divergência quanto a intervenção do superintendente na definição das metas anuais para a escola. Dois apontaram que não há intervenção, mas que a SME/Distrito, por meio dos superintendentes, mantem uma cobrança firme e acirrada não somente na definição quanto no acompanhamento das metas educacionais anuais para a escola. Outros dois informaram que há intervenção e justificam quando apontam, por exemplo, que a escola programa suas metas a partir das propostas pela SME e distritos e que após essa programação o distrito analisa e dá algumas sugestões, fazendo intervenções, inclusive in loco, quando os superintendentes vão até a escola e através de uma conversa dão o feedback para corroborar ou modificar as tais metas:

"E em relação ao plano de metas da escola, a Superintendência Escolar realiza intervenções nesse plano, no sentido, por exemplo, se o diretor estabeleceu uma meta que julgamos incipiente, que não contempla, de fato, aquilo que ele pode atingir, sugerimos que ele coloque uma meta mais desafiadora; ou então, se ele está indo muito, isso é mais difícil de acontecer, mas, se ele coloca uma meta muito superior aquilo que, de fato, ele tem condições de atingir, também pontuamos. Nós vemos se ele, de fato, está cumprindo o protocolo para elaboração dessas metas. Porque cada meta tem um protocolo, uma forma correta de calcular. Então, a gente faz também essa verificação para ver se o diretor está estabelecendo a meta, tal como deve ser realmente." (S????)

Este relato mostra o quanto 0 trabalho do superintendente interfere na gestão escolar, confirmando as percepções dos gestores escolares aludidos anteriormente. Mas, embora esta interferência seja evidente, os diretores afirmam não se sentirem incomodados e encaram como ações positivas, em que as discussões e tomadas de decisões tendem a ser realizados numa base formal, de cooperação e reflexão conjunta tendo em vista a construção de acordos, ao contrário de uma postura diretiva por parte dos superiores hierárquicos: coordenadores de distrito, de gestão escolar e de ensino. Isso fica claro no depoimento de uma superintendente ao afirmar que "como a política da Secretaria é, de fato, o alcance de resultados educacionais, então há um investimento muito direcionado na questão do plano de metas, para que o gestor possa elaborar aquelas metas que ele precisa alcançar, de acordo com a caminhada da escola" (S5). 
Esse tipo de ação demonstra que o trabalho do superintendente é desenvolvido num modelo hierárquico ambivalente e híbrido, pois, de um lado, simetriza relações e, do outro, há uma coordenação com o sentido carismático. Ou seja, "a estrutura de governança híbrida apresenta instrumentos de incentivos, sem deixar de considerar também controles administrativos, combinando adaptação autônoma e adaptação coordenada" (Santos; Mira, 2014, p. 2).

\section{Superintendentes e diretores escolares em movimento: atuação nas escolas}

A amostra da pesquisa constituiu-se de quatro superintendentes escolares pertencentes aos Distritos de Educação I, III, IV e V. Dados relativos à idade e tempo de serviço revelaram que os superintendentes são mais jovens que os diretores escolares. A média de idade é de 37 anos e a média do tempo de magistério é de 13,5 anos; o tempo de exercício no cargo de superintendente escolar é de 5 anos e o tempo de experiência no serviço público é de 12,2 anos. Vale ressaltar que, dentre as entrevistadas, todas são docentes concursadas da rede pública municipal de Fortaleza/CE.

Atualmente, na rede pública municipal de Fortaleza/CE, existem 51 superintendentes escolares distribuídos da seguinte forma: sete no órgão central e 44 nos órgãos regionais, sendo sete em cada um dos Distritos I, II, III e V e oito nos Distritos IV e VI. Essa divisão da quantidade de escolas por superintendente é, segundo eles, um meio de viabilizar a eficácia do acompanhamento e monitoramento, tanto dos gestores escolares, quanto dos estabelecimentos de ensino como um todo.

De acordo com os superintendentes pesquisados as visitas às escolas acontecem mensalmente e obedecem a um protocolo que envolve um cronograma de viagens e uma pauta de acordo com as demandas da SME ou dos Distritos e, também, as necessidades de cada escola. Duas superintendentes afirmaram que as visitas são realizadas num turno e as outras duas disseram que são realizadas em dois turnos. Isso acontece porque, às vezes, não há condições de concluir toda a pauta mensal em meio período. Já as visitas em escolas que funcionam em três turnos são diferentes, consistindo no agendamento de um dia no mês para acompanhar a escola à noite.

As superintendes reconhecem que as exigências do trabalho são muito altas, ao afirmarem que "é muito puxado, porque são demandas que aparecem assim, de última hora, e você tem que dar conta e você tem que correr para atender e tal" (S3) ou que

"não consegue resolver tudo porque a demanda é grande e nem sempre a SME tem perna para atender tudo ao mesmo tempo. Mas a gente tem um critério de prioridade, de atendimento. A gente tem uma escala de uma ordem, do que atender primeiro. Mas a gente sempre atende tentando dar o maior suporte possível a escola." (S3)

Outros detalhes a se destacar nos depoimentos das superintendentes é o fato de que as visitas não costumam ser agendadas; a quantidade de visitas às creches conveniadas é pequena e há problemas quanto ao transporte institucional para realização das atividades.

Complementarmente à pauta, para se obter um panorama do cotidiano da escola, é realizada uma caminhada pedagógica pela superintendente junto com o diretor escolar, observando e monitorando no espaço escolar aspectos como a limpeza, a organização 
geral, as relações do diretor com demais membros da equipe, alunos e pais; a infraestrutura física e como ela se relaciona com o uso dos diferentes espaços e rotinas. Os superintendentes tentam perceber no que os diretores prestam atenção e o que é importante mas lhe passa despercebido. O objetivo principal desta prática é que os diretores sejam auxiliados na leitura do contexto escolar em que estão mergulhados, obrigando-os a dispor de tempo para se dedicar a observação de professores, funcionários e oferecer um feedback oportuno sobre o impacto das práticas.

Os diretores escolares são afetados diretamente pelo trabalho dos superintendentes, por isso, o interesse em captar suas percepções sobre eles. Os entrevistados destacaram o papel do superintendente escolar como positivo, atuante, apoiador, o que destaca a importância que todos dão a esse profissional na rede municipal, inclusive fazendo comparativos de antes e depois da sua criação. Outrossim, um ponto apontado entre os diretores é que se sentem avaliados diariamente pelos superintendentes e que isso contribui para estarem bem e continuarem a buscar melhorias. Um terceiro apontamento dos diretores foi quanto à necessidade de responderem rapidamente as várias demandas dos superintendentes escolares.

No que se refere à gestão da aprendizagem é perceptível o uso de mecanismos de responsabilização educacional, tanto de alto, quanto de baixo impacto junto aos diretores das escolas pesquisadas, posto que prestam contas, tem previsão de premiação, calculam metas e divulgam resultados. Quanto à gestão da aprendizagem a postura dos superintendentes escolares é atuar junto aos diretores para melhorar os resultados da escola. Segundo uma superintendente, após cada ciclo de visita ocorre um encontro com a equipe gestora da escola no Distrito e nesse momento são feitas observações sobre os indicadores educacionais atingidos em relação a aprendizagem dos estudantes. Inclusive, explica que, quando necessário, o superintendente vai até à escola com um técnico em educação - geralmente da Célula de Ensino do Distrito a que a escola pertence -, para dar apoio ao professor, analisar o que está faltando, tudo para que aquela turma avance na aprendizagem.

A percepção dos diretores é que o superintendente não está preocupado somente com a dimensão cognitiva associada aos conteúdos curriculares e as notas dos alunos, mas também com aspectos relacionados a aquisição de habilidades, atitudes, hábitos e competências. Desta forma as preocupações do superintendente com a aprendizagem dos alunos de uma determinada escola, estão organicamente relacionadas ao modelo de gestão por resultados implementado pela SME, que se pauta pela atribuição de valor sobre o grau de eficiência, eficácia, efetividade e viabilidade do processo de ensino promovido pelos professores e pelas escolas.

Também foi citado pelos entrevistados que é aplicado nas escolas do município de Fortaleza/CE um sistema de avaliações diagnósticas - iniciais, intermediárias e finais com todos os alunos de ensino fundamental com foco nas disciplinas de língua portuguesa e matemática. Ela se caracteriza como uma avaliação externa na medida em que não são elaboradas pela escola, mas pela SME e servem para diagnosticar o quanto o aluno avançou, ou se ele continua com deficiências na aprendizagem, verificando se o aluno está no nível muito crítico, crítico, intermediário ou adequado; detectando onde 
podem realmente intervir, que descritor tem que trabalhar mais, por exemplo. Pode-se afirmar, então, que a Superintendência Escolar, no cotidiano da escola, veio preencher uma lacuna de conhecimento dos profissionais em relação aos objetivos, instrumentos e usos dos resultados das avaliações externas.

No que se refere ao trabalho da Superintendência Escolar na gestão administrativa e financeira da escola nenhum dos diretores confirma o apoio deles em questões relacionadas a este setor. Em sua visão são os conselhos escolares com quem compartilham as decisões sobre aplicação, gasto e prestação de contas dos recursos financeiros.

As superintendentes por sua vez, afirmaram que acompanham os conselhos escolares por meio das atas de reuniões, mas não participam dessas reuniões, nem das discussões dos conselheiros:

"O diretor não nos convida para participar da reunião do conselho. Pode acontecer esporadicamente de presenciarmos esse momento na escola, mas assim, de que essa participação seja é [...] organizada, que venham, que a escola comunique que vai fazer naquele dia para que a gente possa participar, isso não existe, não." (S5)

$\mathrm{Na}$ visão dos diretores escolares não há relação de subordinação dentro da estrutura da SME entre os superintendentes e as escolas. Embora, de fato, não exista subordinação formal na percepção dos diretores, na prática, as funções dos superintendentes - verificar, avaliar, orientar, corrigir e realimentar - pressupõe o exercício de alguma relação de poder que pode desequilibrar a horizontalidade da relação. Por pertencerem a uma estrutura regional e assim agirem nas visitas às escolas, com atribuições claramente definidas e entendidas no âmbito da correição, auditoria, orientação e assistência técnica-administrativa e pedagógica, os superintendentes são detentores de informações sobre cada escola, por vezes, antes mesmo da escola visitada saber, já que na atualidade, a dataficacion da educação é cada vez maior (Williamson, 2019; Manolev; Sullivan; Slee, 2019) e mais utilizada "para entender os processos e impactos da crescente governança baseada em dados e regimes de responsabilidade" (Roberts-Holmes; Bradbury, 2016, p. 1).

A aparente autonomia da escola e a ausência de hierarquia a que alude os diretores pode estar relacionado a um controle sem mãos ou, na versão atual, como um controle digitalizado, exercido através de plataformas virtuais, em que os incentivos substituem as restrições, a autodireção impõe-se à coerção, a individualização da consciência orienta-se para o rendimento. Neste caso, a autonomia é uma prática disciplinadora: aumenta a sensação de poder dos indivíduos ao mesmo tempo que os torna mais dóceis e disciplinados: "a autonomia é o panóptico da moderna organização educativa" (Ball, 2001, p. 86).

\section{Dimensões das reformas na gestão educacional de Fortaleza}

As alterações introduzidas a partir de 2013 na gestão educacional de Fortaleza/CE ocorrem a partir de alguns elementos de contexto. De um lado, as mudanças na política educacional em âmbito nacional, com o protagonismo que as avaliações de larga escala começam a adquirir e a mobilização dos sistemas de ensino a desenvolver estratégias 
administrativas, pedagógicas e de responsabilização para se adequar a estes novos tempos, em que as escolas são as células de produção de resultados educacionais. De outro, o alinhamento político dos dois governos - estadual e municipal -, criou uma ambiência em que os modelos e sistemas implementados no âmbito do Estado migraram para o município, inclusive com a cessão de técnicos qualificados de uma rede escolar para a outra. A ideia de criação do cargo de superintendente escolar foi inspirada no modelo estadual e suas funções se identificam com o que é feito nas escolas de ensino médio do Estado e nos órgãos regionais de educação.

A lei complementar n. 169/2014 regulou a criação, implantação, configuração e formatação da Superintendência Escolar na rede pública municipal, funcionando como um marco e um dos principais vetores de mudanças na educação pública deste município no que concerne à gestão educacional e escolar. Os dados empíricos reunidos no âmbito deste estudo revelam que a legislação e as iniciativas práticas - políticas, seleção e chamadas públicas, cursos, formações - parecem ter se constituído numa alternativa viável para a formação e consolidação de uma equipe de profissionais em educação que viabilizem o exercício da gestão escolar, materializando-se na estrutura da administração pública.

Especificamente com relação à seleção de superintendente escolar constatou-se nos documentos legais que desde seu surgimento em 2014, o procedimento adotado foi a seleção pública para gerar o cadastro de reserva e a chamada pública, quando há a vacância do cargo na SME ou Distritos de Educação.

A primeira seleção de superintendentes escolares foi realizada pela Célula de Superintendência Escolar da SME e as etapas consistiram em: $1^{\underline{a}}$ ) provas objetivas e $2^{\underline{a}}$ ) prova de títulos, mantidas também na segunda seleção em 2017 (edital n. 50/2017). O edital de 2017 especificou que a seleção pública tem duas etapas: a primeira constituída por prova objetiva, de caráter eliminatório, para todos os candidatos; e a segunda, com a análise de títulos e experiência profissional, também de caráter eliminatório, válida para os candidatos aprovados na primeira etapa.

As chamadas públicas normatizam que o processo de escolha e indicação para o cargo de superintendente escolar deve ocorrer por meio de entrevista, em que é atribuída nota de 0 a 100 ao candidato, considerando-se os seguintes aspectos: a) liderança, comunicabilidade, criatividade, motivação e visão sistêmica; b) domínio de estratégias e metodologias da gestão escolar e da gestão educacional com foco na aprendizagem; e c) conhecimento das políticas e dos resultados educacionais do sistema municipal de ensino de Fortaleza.

As quatro superintendentes entrevistadas relataram que suas seleções contaram com as seguintes etapas: $\left.1^{\circ}\right)$ seleção pública de provas e títulos; $2^{\circ}$ ) chamada pública; e $\left.3^{\circ}\right)$ entrevista. No caso das entrevistas, estão são realizadas com os candidatos que se encontram no cadastro de reserva, quando ocorre vacância na SME ou nos Distritos de Educação.

A pesquisa documental identificou apenas uma portaria que trata da criação de comissão de seleção - portaria n. 124/2013 -, porém, não detectou critérios objetivos previstos nesse ou em outros documentos oficiais, para a seleção de candidatos ao provimento dos cargos de superintendente escolar. Os vários editais examinados revelaram a ausência de critérios objetivos para análise, correção e pontuação dos itens

\begin{tabular}{|l|l|l|l|l|l|}
\hline Regae: Rev. Gest. Aval. Educ. & Santa Maria & v. 10 & n. 19 & e61908, p. 1-20 & 2021 \\
\hline
\end{tabular}


que seriam considerados na entrevista de cada candidato. Assim, os processos seletivos resumem-se em avaliações de caráter subjetivo, sem que ao menos fossem estipulados previamente os critérios de pontuação para a mesma. Com base na pontuação total é elaborada uma lista com a classificação dos candidatos que, antes de ser divulgada no site oficial da Secretaria, é compartilhada e submetida à Secretária de Educação para análise e aprovação final da relação dos candidatos selecionados.

Ressalte-se que, em geral, esse propenso candidato a superintendente escolar não precisa necessariamente ter curso em nível de pós-graduação em tema relacionado à gestão ou liderança escolar; nem estar ou ter estado em cargo de gestão escolar, e também, não há nenhum empecilho em ter exercido somente funções fora de sala de aula em cargos técnicos. Seu histórico como professor e gestor interessa e será contabilizado, caso seja aprovado na primeira fase da seleção.

Também não foi encontrada indicação de pré-requisitos específicos que relacione o cargo aspirado à formação, à experiência e às características da instituição - porte, localização da escola, quantidade de alunos, etc. - e isso pode ser de considerável importância.

Observou-se que as superintendentes entrevistadas possuem menos tempo e experiência profissional em cargos de gestão do que os gestores de várias escolas. No entanto, constrangimentos em relação a essa situação não foi relatado pelos diretores. Das quatro entrevistadas não possuíam experiência anterior em cargo de direção escolar ou gestão educacional uma relatou que participou de equipe gestora, mas como coordenadora pedagógica.

Como a docência é pré-requisito para o exercício da função ou cargo, tanto de diretor de escola, quanto de superintendente escolar, denota-se, no caso das entrevistadas, que todas preservam seu estatuto profissional docente. Porém, é perceptível que os diretores ainda olhem e percebam a escola de maneira bastante parecida aos professores que são, mas, tanto eles, quanto os superintendentes, agregam outros elementos que passam a integrar a rotina da nova função desempenhada. Assim, pode-se afirmar que a maneira como as entrevistadas constroem sua identidade profissional está associada a processos de continuidade e rupturas.

Todas os superintendentes se avaliam com um bom grau de conhecimento sobre as tarefas inerentes aos gestores escolares e isso é detectado nas manifestações de cada um deles. A maneira como atribuem significado as suas experiências de trabalho nos remete a crer que esta acontece por meio de aprendizagem incidental, isto é,

por intermédio de experiências no local de trabalho - no processo de realizar tarefas; por observação, repetição, interação social e resolução de problema; ao falar com colegas ou experts sobre qualquer tema; quando se cometem erros ou deduzem-se suposições; em um processo de adaptação/aceitação de situações - porém elas somente são percebidas como aprendizado depois de ocorrida a situação, ou seja, não há a intenção do aprender, mas, por fim, há aumento de conhecimento e habilidades. (Camillis; Antonello, 2010, p. 16)

A SME deve acreditar que "a participação em processos, em situações do dia a dia de trabalho das e nas organizações é também fonte de aprendizagem" (Antonello, 2004, p. 7). Não há dados sobre a taxa de rotatividade de superintendentes escolares, mas 
pode-se perceber pelos relatos que ela existe e que está associada com a definição de um amplo conjunto de atribuições cujas demandas provêm dos gestores escolares, do distrito de educação e da própria Secretaria. Nesse sentido, questões como reduzir esforços e aumentar eficiência da seleção se tornam essenciais. O desafio maior está em como implementar essa otimização e, ainda, garantir qualidade e precisão na seleção.

Indubitavelmente a seleção de um superintendente é uma atividade trabalhosa, que carece de muita atenção e critérios bem definidos, afinal, a equipe é essencial para o sucesso que a SME almeja. A gestão da SME precisa analisar a capacidade técnica do profissional e se o seu perfil se enquadra no clima organizacional da Secretaria/Distritos de Educação e, também, das escolas. Para tanto deve observar que existe pelo menos duas formas de promover o aumento do desempenho no trabalho: ou por meio de um bom processo seletivo ou por ações de treinamento e desenvolvimento do candidato selecionado (Hilliard, 2000).

No que diz respeito ao trabalho dos superintendentes escolares constatou-se que eles:

a) passam mais tempo coletando e sintetizando informações do que analisando-as, portanto, preferem resumir as diferentes partes a analisar as mesmas e expor sua essência;

b) não têm tempo para testar métodos novos e nem pensar sobre aqueles que falharam antes de serem descartados para refletir ou analisar problemas que a escola enfrenta, o que ocasiona um sentimento de frustração;

c) são forçados a admitir que ignoram alguns aspectos da gestão escolar e, portanto, precisam perguntar a outra pessoa: um professor, um colaborador administrativo ou mesmo um aluno;

d) dão mais importância ao que foi dito do que a quem o disse, não importa de onde venha uma revelação sobre a realidade da escola;

e) não tentam aplicar fórmulas pré-estabelecidas para resolver problemas: examinam cada problema separadamente e procuram uma solução eficaz;

f) enfrentam e tentam resolver todos os tipos de problemas, dos mais simples aos mais complexos, recriando mentalmente as soluções para um problema e não descartam as diferentes alternativas que muitos outros podem pensar;

g) agem sob pressão constante da SME e dos Distritos;

h) articulam e expressam a filosofia de trabalho da SME;

i) tem contato com colaboradores de todos os níveis da escola;

j) são muito receptivos, solidários e calorosos com as pessoas;

k) concentram-se nos pontos fracos da escola.

\section{Considerações finais}

O estudo sobre a gestão educacional da rede municipal de Fortaleza permitiu lançar um olhar mais atento sobre a criação de um novo cargo no âmbito da SME e dos Distritos de Educação em 2013, momento marcado por uma mudança no modelo de gestão por parte do governo municipal eleito. Ao adotar a gestão por resultados a SME reorganizou o fluxo de atendimento e monitoramento às escolas, criando a superintendência escolar, tanto nos Distritos, quanto no órgão central. 
Essa iniciativa procurou estender a capacidade de controlar um sistema descentralizado que envolve 299 escolas distribuídas em 6 distritos educacionais. A criação deste novo cargo se alinha com os princípios da nova gestão pública e os pressupostos que orientam as políticas educacionais em curso, com destaque para a valorização da medição de um conjunto de indicadores educacionais incluindo os resultados de desempenho dos alunos nas avaliações de larga escala.

Em decorrência dessas novas atribuições dos superintendentes fluxos de processos foram redesenhados e a escola passou a ter a responsabilidade de atingir metas previamente definidas. Embora os depoimentos mostrem um clima amigável e cordial de trabalho entre superintendentes e gestores escolares, é perceptível que a autonomia da gestão escolar foi afetada.

Os depoimentos dos superintendentes, por sua vez, revelam que o cargo tem um padrão de exigência e de atribuições complexo, uma vez que funciona como uma interface entre a gestão superior e as escolas, requerendo competências técnicas e habilidades profissionais de ordem superior, cuja formação originária para a docência não fornece e que as eventuais formações continuadas não preparam para tal empreendimento. Percebeu-se, também, que há um esforço por parte desses atores em fomentar as interações interpessoais no intuito de criar um ambiente de trabalho agradável, o que permite uma boa aceitação do seu trabalho por parte da escola.

No que tange às percepções dos gestores escolares sobre o trabalho da superintendência, a aceitação incondicional, sem uma reflexão sobre de que forma este trabalho afeta a autonomia da escola, parece ingênua ou conveniente. Pelos depoimentos dos gestores eles se sentem pressionados, cobrados e responsabilizados pelos resultados de suas escolas, no entanto, consideram o superintendente um parceiro na busca pelos resultados. Seria um tipo de parceria que ajuda o gestor a melhorar seus processos de gestão por meio de uma indução deliberada com vistas à atingir determinados resultados planejados e desejados pelo sistema de ensino.

\section{Referências}

AFONSO, Almerindo Janela. Nem tudo o que conta em educação é mensurável ou comparável. Crítica à accountability baseada em testes estandardizados e rankings escolares. Revista Lusófona de Educação, Lisboa, v. 13, n. 13, 2009, p. 13-29.

ALVES, Jurema Silvia de Souza Alves; SÁ, Maria Auxiliadora Ávila dos Santos. Incidentes críticos nas trajetórias profissionais de gestores escolares. Revista Eletrônica de Educação, São Carlos, v. 9, n. 3, 2015, p. 321-341.

ANTONELLO, Claudia Simone. As formas de aprendizagem utilizadas por gestores no desenvolvimento de competências. ENCONTRO NACIONAL DOS PROGRAMAS DE PÓS-GRADUAÇÃO EM ADMINISTRAÇÃO, 28, 2004. Anais... Curitiba: Anpad, 2004.

BALL, Stephen J. Cultura, costes y control: la autonomía y la enseñanza de carácter empresarial en Inglaterra y Gales. In: SMYTH, John (ed.). La autonomía escolar: una perspectiva critica. Madrid: Akal, p. 77-97, 2001.

BARROSO, João. A transversalidade das regulações em educação: modelo de análise para o estudo das políticas educativas em Portugal. Educ. Soc., Campinas, v. 39, n. 145, 2018, p. 1075-1097. 
BARROSO, João. O estado, a educação e a regulação das políticas públicas. Educ. Soc., Campinas, v. 26, n. 92, 2005, p. 725-751.

BORDIGNON, Genuíno. Gestão da educação no município: sistema, conselho e plano. São Paulo: Instituto Paulo Freire, 2009.

BRASIL. Emenda constitucional n. 59, de 11 de novembro de 2009. Brasília: DOU, 12 nov. 2009.

CAMILLIS, Patrícia Kinast de; ANTONELLO, Claudia Simone. Um estudo sobre os processos de aprendizagem dos trabalhadores que não exercem função gerencial. Rev. Adm. Mackenzie (Online), São Paulo, v. 11, n. 2, 2010, p. 4-42.

CHIAVENATO, Idalberto. Introdução à teoria geral da administração. Rio de Janeiro: Elsevier, 2004.

COSTA, Anderson Gonçalves. A política educacional cearense no (des)compasso da accountability. Fortaleza: UECE, 2020. 156f. Dissertação (Mestrado em Educação). Programa de Pós-Graduação em Educação, Universidade Estadual do Ceará.

DEWEY, John. Democracy and education: an introduction to the philosophy of education. New York: Free Press, 1916.

DOURADO, Luiz Fernandes. Políticas e gestão da educação básica no Brasil: limites e perspectivas. Educ. Soc., Campinas, v. 28, n. 100, 2007, p. 921-946.

DRABACH, Neila Pedrotti. Processos de provimento: exigências e atribuições para os dirigentes escolares em contextos de reformas gerencialistas. Campinas: Unicamp, 2018. 265f. Tese (Doutorado em Educação). Universidade Estadual de Campinas.

FALSARELLA, Ana Maria. Equipe gestora e formação docente: do discurso à prática escolar. Araraquara: Junqueira \& Marin, 2018.

FERREIRA, Lice Helena. Os mecanismos de controle da organização capitalista contemporânea na gestão escolar pública paranaense (1995-2002). Curitiba: UFPR, 2006. 204f. Dissertação (Mestrado em Educação). Programa de Pós-Graduação em Educação, Universidade Federal do Paraná.

FONSECA, Marília; OLIVEIRA, João Ferreira de. A gestão escolar no contexto das recentes reformas educacionais brasileiras. RBPAE, Brasília, v. 25, n. 2, 2009, p. 233246.

FORTALEZA. Edital n. 050/2017-Imparh. Fortaleza: Prefeitura Municipal, 2017.

FORTALEZA. Lei Municipal n. 8.608, de 26 de dezembro de 2001: dispõe sobre a organização administrativa da Prefeitura Municipal de Fortaleza e dá outras providências. Fortaleza: Prefeitura Municipal, 2001.

FORTALEZA. Lei complementar n. 0169/2014, de 12 de setembro de 2014: institui o Programa Municipal de Manutenção e Desenvolvimento do Ensino, modifica o Estatuto do Magistério de Fortaleza. Fortaleza: Prefeitura Municipal, 2014.

FORTALEZA. Decreto n. 14.450, de 12 de junho de 2019: dispõe sobre a estrutura organizacional, a distribuição e a denominação dos cargos em comissão da Secretaria Municipal da Educação (SME), na forma que indica. Fortaleza: Prefeitura Municipal, 2019.

FORTALEZA. Portaria n. 124/2013, de 17 de maio de 2013: institui e nomeia a comissão coordenadora da seleção pública para os cargos em comissão de diretores e vicediretores das escolas da rede municipal de ensino. Fortaleza: Prefeitura Municipal, 2013. 
FRIGOTTO, Gaudêncio; CIAVATTA, Maria. Educação básica no Brasil na década de 1990: subordinação ativa e consentida à lógica do mercado. Educ. Soc., Campinas, v. 24, n. 82, 2003, p. 93-130.

GRACINDO, Regina Vinhaes. O gestor escolar e a dinâmica democrática na educação. Revista Retratos da Escola, Brasília, v. 3, n. 4, 2009, p. 135-147.

HILLIARD, Pearl Augustine. Comparison of the predictive validity of a written test, an integrity test, a conscientiousness questionnaire, a structured behavioral interview and a personality inventory in the assessment of job applicants background investigations, and subsequent task and contextual job performance Criterion-related validity of a measure of person-job and person-organization fit. Los Angeles: USC, 2000. 117f. These (Doctor of Education). University of Southern California.

HOLANDA, Marcos Costa (org.). Ceará: a prática de uma gestão pública por resultados. Fortaleza: Ipece, 2006.

LIBÂNEO, José Carlos; OLIVEIRA, João Ferreira de; TOSCHI, Mirza Seabra. Educação escolar: políticas, estrutura e organização. São Paulo: Cortez, 2003.

MANOLEV, Jamie; SULLIVAN, Anna; SLEE, Roger. The datafication of discipline: ClassDojo, surveillance and a performative classroom culture. Journal Learning, Media and Technology, England, v. 1, n. 44, 2019, p. 36-51.

MARTINO, Mariluci Alves. A importância das parcerias na educação profissional. São Paulo: PUC, 2006. 221f. Dissertação (Mestrado em Educação). Pontifícia Universidade Católica de São Paulo.

OLIVEIRA, Dalila Andrade. Educação básica: gestão do trabalho e da pobreza. Petrópolis: Vozes, 2000.

PARENTE, Juliano Mota. Gestão escolar no contexto gerencialista: o papel do diretor escolar. Roteiro, Joaçaba, v. 42, n. 2, 2017, p. 259-280.

PARO, Vitor Henrique. Formação de gestores escolares: a atualidade de José Querino Ribeiro. Educ. Soc., Campinas, v. 30, n. 107, 2009, p. 453-467.

PINA, Raul Manuel da Fonseca Janeiro Tavares. Da liderança do diretor aos resultados escolares dos alunos: um caminho a percorrer. Porto: UCP, 2015. 386f. Tese (Doutorado em Ciências da Educação). Universidade Católica Portuguesa.

QUEIROGA, Fabiana. Seleção de pessoas e desempenho no trabalho: um estudo sobre a validade preditiva dos testes de conhecimentos, Brasília: UNB, 2009. 223f. Tese (Doutorado em Psicologia Social, do Trabalho e das Organizações). Universidade de Brasília.

ROBERTS-HOLMES, Guy; BRADBURY, Alice. Governance, accountability and the datafication of early years education in England. British Educational Research Journal, England, v. 42, n. 4, 2016, p. 600-613.

SANTOS; Adriana Reis; MIRA, Elson Cedro. A Importância da Estrutura de Governança Híbrida na Economia Contemporânea. Semana do Economista e Encontro de Egressos de Economia da UESC, 4, 2014. Anais... Ilhéus: UESC, 2014, p. 1-20.

SOLANO ALPÍZAR, José. Educación y gestión en América Latina. Revista Eletrónica Educare, Costa Rica, 2005, v. 8, p. 49-57.

SOUZA, Lânia Daniela Marta; RIBEIRO, Marcelo Silva de Souza. Perfil do gestor escolar contemporâneo: das permanências as incorporações para exercício da função. Espaço do Currículo, João Pessoa, v. 10, n. 1, 2017, p. 106-122. 
THIÉTART, Raymond-Alain. Méthodes de recherche en management. Dunod: Paris, 2014.

YIN, Robert K. Estudo de caso: planejamento e métodos. Porto Alegre: Bookman, 2003.

WILLIAMSOM, Ben. Datafication of education: a critical approach to emerging analytics technologies and practices. In: BEETHAM, Helen; SHARPE, Rhona (eds.). Rethinking pedagogy for a digital age. London: Routledge, 2019.

Esmeraldina Sousa de Sousa é professora e supervisora escolar na rede pública municipal de Fortaleza/CE.

Orcid: https://orcid.org/0000-0003-3349-0838.

Endereço: Avenida Sargento Hermínio Sampaio, 1415/303a - Bloco Tulipas 60326-500 - Fortaleza - CE - Brasil.

E-mail: esmeraldinajs@gmail.com.

Eloisa Maia Vidal é professora no Programa de Pós-Graduação em Educação da Universidade Estadual do Ceará.

Orcid: https://orcid.org/0000-0003-0535-7394.

Endereço postal completo: Avenida Santos Dumont, 3210/104C - 60150-162 -

Fortaleza - CE - Brasil.

E-mail: eloisamvidal@yahoo.com.br.

Recebido em 20 de outubro de 2020.

Aceito em 4 de janeiro de 2021.

(c) $(1) \otimes(\Theta$ 